\title{
Construction of Cost and Schedule Equilibrium Control Model for Communication Base Stations Project
}

\author{
Guoqing Dang ${ }^{1, \text { a }}$ \\ ${ }^{1}$ School of mechanical engineering, XINYU University, XINYU 338031, China \\ a Dangguoqing@126.com
}

Keywords: Cost and Schedule Equilibrium Control, Communication Base Station, Earned Value Method

\begin{abstract}
With the increasing number of project construction, the shortening of engineering period and the continuous improvement of quality requirements have promoted the advanced experience of project management in the construction of network. The construction quality of base station and the construction period of base station have become the decisive factor. This paper discusses the application of the theory and method of modern project management in the construction of telecommunication network communication network. The significance of this thesis is to find out the rational application pattern of project management in the construction of communication network so as to make the construction of communication network more scientific and scientific, so as to reduce the cost of the enterprise and improve the efficiency and competitiveness of the enterprise.
\end{abstract}

\section{Introduction}

Communication base station construction area wide, the process is very complex, involving the large scale, the construction link between the great jump, the difficulty of the implementation of a larger project ${ }^{[1]}$. Therefore, the base station construction quality and base station construction cycle has become a decisive factor, on the one hand will directly lead to the base station put into use time, on the other hand, and maintenance costs. The stability of the network operation is directly linked. It can be seen that the guiding principle of advanced project management philosophy as a base station construction project is important, and it can be idealized for the progress, quality and cost of the project. It is a natural protection for the construction quality of the base station and the progress of the project. Barrier for the mobile communications industry to seize more market share, and for enterprises to build brand effect to lay a good foundation. Therefore, it is of practical significance to study the construction cost and progress control of communication base station.

Earned Value Management (EVM), as a method of project cost and schedule control in international project management theory, has been widely used in international project management due to the use and success of large-scale national defense projects in the United States. ${ }^{[2]}$ This paper mainly analyzes the problems existing in the management of the communication base station and the management of the progress of the communication base station, and then studies how to build the integrated cost control model of the communication base station based on the Earned value method. Earned value method for cost and schedule of comprehensive control, to make the project cost targets and progress objectives to be better guaranteed. In the preparation of the plan can take full account of the project funding situation, to avoid the implementation of the project due to the lack of funds in place of the progress of the situation. During the execution of the project, the cost situation can be accurately tracked and predicted, so as to avoid the emergence of cost overruns. In addition, project progress is effectively quantified and forecasted.

\section{Base station construction project characteristics}

Mobile communication network mainly by the exchange system and the base station system 
composed of two parts, which rely on fiber optic transmission system for transparent transmission. The former system is different from the traditional voice and fixed telephone exchange system, but the function and interface are improved. The base station system is the core construction part of the mobile network. Its equipment selection and network construction determine the basic quality of service of the wireless mobile network. Base station construction of the total investment accounted for more than $60 \%$ of mobile network construction. The base station system logically includes the base signal transmission station (referred to as base station) BTS and the base station management system BSC ${ }^{[3]}$. However, in the actual project, because the BSC module is basically with the switch room mobile business exchange MSC coexistence of a room, therefore, BSC construction is classified into the switch construction projects, and a large number of scattered base station system equipment BTS is another separate project tender. Therefore, the construction of the base station project referred to in our project refers to the unmanned BTS room construction and equipment installation in cities, villages, roads, fields and large buildings. It is the core component of the wireless communication network. Construction investment, operation and maintenance costs are high, involving the intermediate links cumbersome, many participants, the construction of large span, the implementation of the project is relatively complex, is the wireless network investment and construction of the main project ${ }^{[4]}$.

Mobile base station construction project is divided into:

1) Wireless base station site selection, exploration, confirmation,

2) Alternative site construction. Complete the engine room, tower, exchange the introduction of basic supporting the construction, battery, switching power supply, antenna and other ancillary equipment installation and BTS main equipment installation.

3) Complete the base station planning, including base station carrier frequency configuration, wireless data planning (such as attribution MSC, BSC, LAC, etc.), and base station circuit requirements.

4) Base station opening phase, including the transmission circuit is opened, the base station and the introduction of planning data and so on.

\section{Earned value theory}

Earned Value Management (EVM) is based on the earned value of the work budget, measuring the cost and progress of the project with three basic values, and comprehensively measuring and reflecting the progress of the project. Which is mainly calculated by calculating the budgetary costs of the completed work costs and the actual costs of the work and the budgetary costs of the planned work $^{[5]}$. The estimated costs and schedule deviations and performance indicators of the planned implementation, through which the indicators are used to estimate the completion of the project, Project costs and the implementation of the progress plan. The theory coincides with the goals and principles of the cost and progress control model to be built ${ }^{[6,7]}$.

1) Planning Value (PV) is the planned activities or work breakdown structure components need to complete the progress of the provisions of the distribution of work and approved budget, that is, to plan the work of the budget cost (Budgeted Cost of Work Schedule, BCWS). That is, during the implementation of the project B in the implementation of paragraph B to check the effect of the implementation of the specified time within the specified schedule should be completed the cost of the budget, reflecting the schedule should be completed by the workload.

$$
P V(t)=B C W S(t)=\sum_{0}^{t} P Q_{t} \times S C,(0 \leq \mathrm{t} \leq \mathrm{T})
$$

Where $t$ is the current detection point. $T$ is the project end time. PQ is the planned workload. SC is the cost of the budget.

(2) Earned Value (EV) is Budgeted Cost of Work Performed (BCWP) for the actual completion of an activity or work breakdown structure component within a given period of time. That is, the implementation of the communication base station construction process to check the effect of the 
implementation of the workload has been completed by the budget fixed amount of the cost of the project to reflect whether the project implementation of the progress of the contract plan.

$$
E V(t)=B C W P(t)=\sum_{0}^{t} A Q_{t} \times S C,(0 \leq \mathrm{t} \leq \mathrm{T})
$$

Where $t$ is the current detection point. $T$ is the project end time. AQ is the actual workload. SC is the cost of the budget

(3) Actual Cost (AC) The actual expenses incurred for the completion of the project (including all completed and partially completed), regardless of the project's budgeted costs. That is, the actual cost of work in the construction of the base station construction project has been completed.

$$
A C(t)=A C W P(t)=\sum_{0}^{t} A Q_{t} \times A C,(0 \leq \mathrm{t} \leq \mathrm{T})
$$

Where $t$ is the current detection point. $T$ is the project end time. AQ is the actual workload. AC is the actual unit cost.

\section{Construction of cost and schedule equilibrium control model}

The construction project cost and schedule control model which is suitable for the construction of communication base station in this paper has three main parts: information tracking, information analysis and information feedback. The information analysis includes three basic value calculation modules, the deviation index and the performance index calculation module and the forecasting index calculation module. The information feedback includes the cost adjustment and the cost adjustment and the cost adjustment module. The information analysis includes the three basic value calculation module, the deviation index and the performance index calculation module and the forecast index calculation module. Progress adjustment module is shown in Fig. 1.

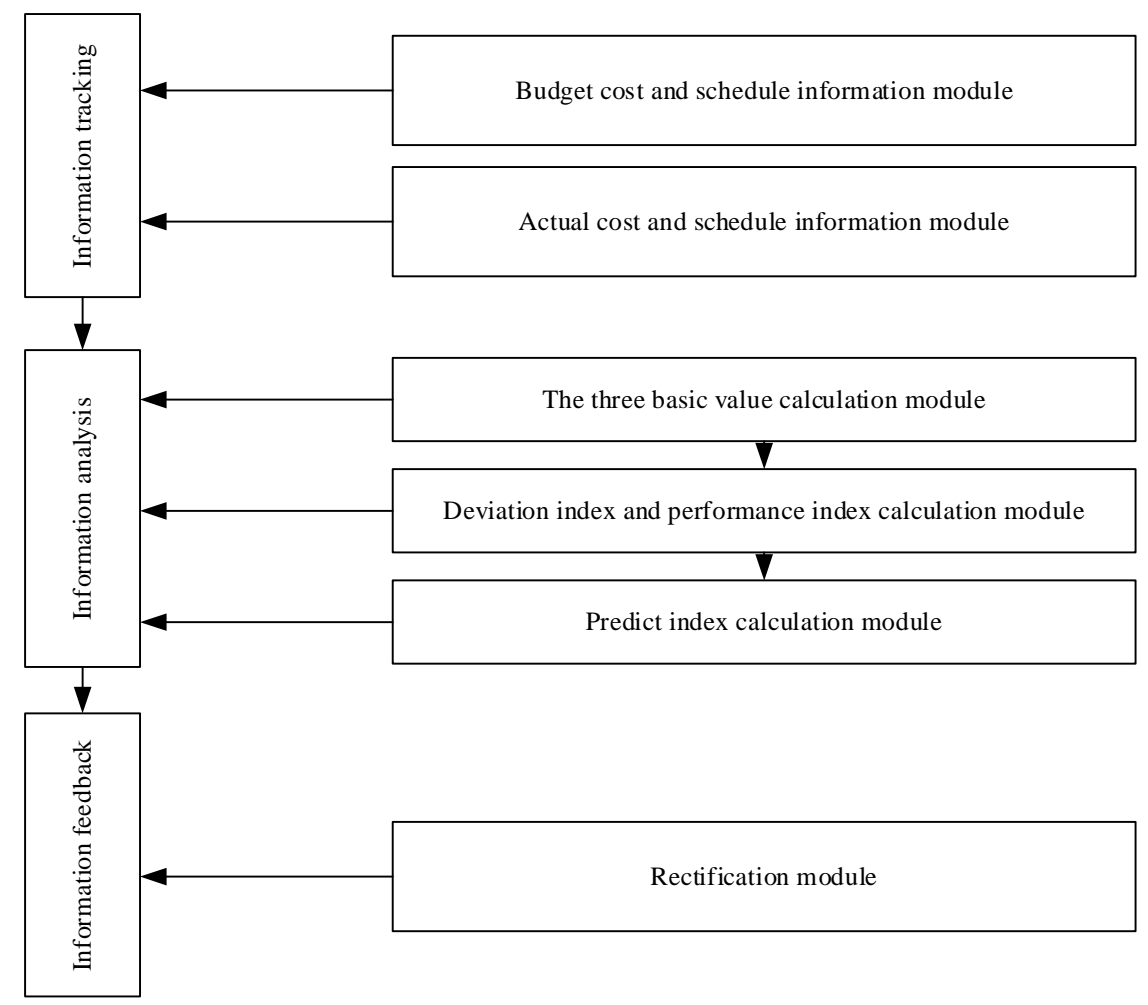

Fig. 1. Cost and schedule equilibrium control model based on EVM

The actual cost table and the actual schedule can be obtained from the data collected by the actual cost and the actual schedule information module. The actual cost table and the actual schedule can be obtained by using the data collected from the budget cost and the schedule information module. The module can calculate the value of each index, and then according to these 
values can be deviation analysis and performance analysis, and then the completion time and completion of the cost of forecasting to find out the reasons for the deviation, timely correction. Cost and schedule control model in the implementation of the communication base station implementation steps:

1) Construction of the decomposition structure: communication base station construction project includes the driving command system and the line ATP/ATO and interlocking system two sub-projects, and these two sub-projects and contains a number of three sub-projects, so the implementation of cost and schedule control model must first WBS decomposition.

2) Determine the total schedule of the project. Combined with weather, environment, personnel and other factors to consider the development of communication base station construction of the overall progress of construction, and to determine the order of each work and planned operating time.

3) Determine the total cost of the project budget. Taking into account the various factors to develop the total cost budget, and spread to all levels of WBS projects, while the allocation of budget to each monitoring point.

4) Establish the three indicators of the secondary project system, draw the second sub-project construction plan progress network map, and determine the key path, indicating the secondary project between the association and time relaxation.

5) Earned value analysis and index forecasting for the second level project respectively, and accumulate the estimated completion cost of the second grade project as the forecast completion cost of the whole project.

6) Combine the progress of the progress of each of the secondary projects in the critical path network to estimate the difference between the actual progress of the project and the planned progress.

7) Analyze the third index system of the two projects, combined with the key path network diagram, drawing the cost and progress trend chart.

8) Analyze the construction of communication base station construction engineering correction and performance causal.

\section{Conclusion}

Mobile communication construction project management has become an important strategic management of enterprise initiatives. This paper introduces the theory and method of project management, and elaborates the practice of project progress management and project quality management theory in communication engineering construction. It points out how to make project management and mobile communication base station project Some practical functions, through the existing cost and schedule control theory analysis and comparison, combined with the actual situation of communication base station construction projects, the use of earnest value theory to build the cost and progress of the integrated control model, the follow-up of the construction of communication base stations Stage of the implementation process to control, to the progress of management and quality control as a means to promote the construction of communication network more scientific, improve the efficiency and competitiveness of enterprises.

\section{Acknowledgements}

2016 Education Science and technology research project in Jiangxi Provincial, Number: GJJ161193.

\section{References}

[1] Wei L. I. The Coordinated Development between Mobile Communication Base Station Construction and Urban Planning__A Case Study of Lianyungang [J]. Journal of Huaihai Institute of Technology, 2012. 
[2] Vanhoucke Mario. Earned Value Management [J]. Project Management with Dynamic Scheduling, 2014, 47(5): 17-31.

[3] Sheynblat Leonid, Wrappe Thomas. Method and apparatus for determining location of a base station using a plurality of mobile stations in a wireless mobile network [M]. Google Patents. 2008.

[4] Nijhof J. A. M., Dewantara I. S., Roovers Ad. J. M., Prasad R. Base station system configurations for future universal mobile telecommunication systems [J]. IEEE Transactions on Vehicular Technology, 1994, 43(3): 659-665.

[5] Lipke Walt, Zwikael Ofer, Henderson Kym, Anbari Frank. Prediction of project outcome: The application of statistical methods to earned value management and earned schedule performance indexes [J]. International journal of project management, 2009, 27(4): 400-407.

[6] Vanhoucke Mario. Earned Value Management [M]. Integrated Project Management Sourcebook. Springer. 2016: 199-250.

[7] Naeni Leila Moslemi, Shadrokh Shahram, Salehipour Amir. A fuzzy approach for the earned value management [J]. International Journal of Project Management, 2014, 32(4): 709-716. 